\title{
POSSIBLE HYBRID PROPULSION CONFIGURATION FOR TRANSPORT JET AIRCRAFT
}

\author{
Sergio CHIESA ${ }^{1}$, Marco FIORITI ${ }^{2}$, Roberta FUSARO ${ }^{3}$ \\ Department of Mechanical and Aerospace Engineering, Politecnico of Turin, \\ Corso Duca degli Abruzzi, 24, 10129, Turin, Italy \\ E-mail: ${ }^{2}$ marco.fioriti@polito.it (corresponding author)
}

Received 22 September 2014; accepted 04 May 2016

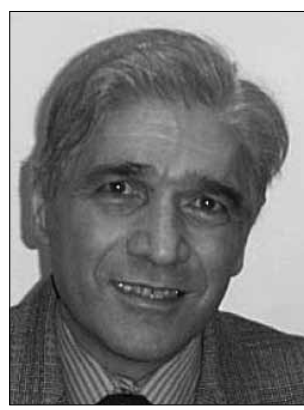

\section{Sergio CHIESA}

Education: 1972, degree of PhD in Aeronautical Engineering at Politecnico di Torino. For three years, he was employed in the field of quality assurance in an Italian firm involved in the Tornado program. In 1976 he enrolled at Turin Polytechnic as an assistant of aeronautical design. Affiliations and functions: since 1978, he has been teaching aeronautical systems, with particular emphasis on reliability and logistic support; since 1990, - he has been working as a a full professor and in the 1991 he was appointed as the chairman of the Aerospace Engineering Department at Politecnico di Torino. He is the author of many technical papers on aircraft systems, aircraft design, and reliability and logistic support. He was a founder of the diploma course in aerospace engineering at Turin Polytechnic. Since the foundation of that program, he has been its chairman. He is the chairman of the council of "Area di Formazione" in aerospace engineering. He is an editorial member of one scientific journal (Journal of Aerospace Engineering), and he works in the "Systems Engineering" research group of the Aerospace Engineering Department.

Experience: a member of SOLE (District 20, Chapter 02, Northern Italy) since 1981. From 1994 to 1997, he was the chairman of SOLE Chapter 02. He is a member of the AIDAA and the chairman of the Turin Section.

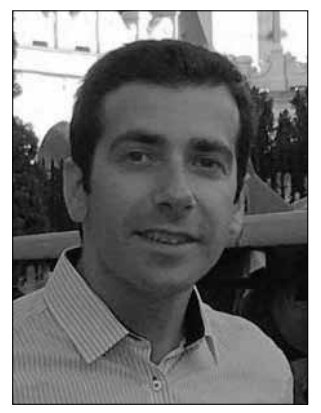

\section{Marco FIORITI}

Education: in 2010, a PhD degree in Aerospace Engineering at Politecnico di Torino. The title of the thesis was "Innovative solutions for light, ultralight and unmanned aircraft". Work experience: since 2010, he has been a researcher in aerospace system engineering at Politecnico di Torino, focusing his research on aircraft conceptual design, on-board systems preliminary design, MDO methodologies, Reliability, Availability, Maintenaibility, Safety disciplines and aircraft Life Cycle Cost estimation algorithms. He has contributed to several national and European reserch programs (SMAT, Clean sky SAGE, Agile H2020) and is the author of several scientific articles and congress proceedings papers.

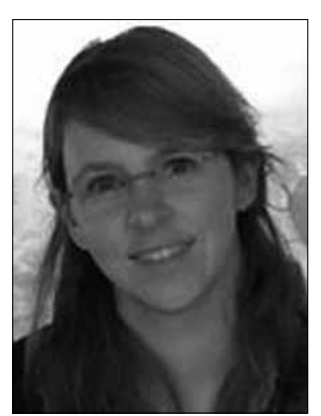

\section{Roberta FUSARO}

She was born in 1989 in Turin and enrolled at Politecnico di Torino in 2008. She completed her Engineering studies in 2013 when she received her MSc Degree. In October 2013, she started her collaboration with the Aerospace Systems Engineering Research Group, in the Mechanical and Aerospace Department of Politecnico di Torino, and, since January 2014, she has been attending a PhD course in Aerospace Engineering. She has contributed, as a co-author, to some scientific articles and congress proceedings papaers, and her research is aimed at Aircraft Conceptual Design, with a focus on UAVs, hypersonic transportation systems, hybrid propulsion and simulation methodologies.

Abstract. This research is aimed at studying the possible advantages of installing, for a hybrid propulsion aircraft, electric motors and related propellers into the dedicated supplementary nacelles. This innovative solution is different from the configuration, already studied for a regional turboprop (Chiesa et al. 2013), in which the electric motors are in the same nacelles of the internal combustion engines. As it has been expected, it offers the advantages of avoiding 
mechanical links between the two units and, more importantly, can also be applied to jet aircraft. In fact, the main contribution of electric motors is expected during ground operations, take-off and descent phases (i.e. at low speed), in which it can be useful to integrate the propellers or even substitute the jet engines with them. At high speed, the propellers, of course, are configured in order to reduce drag. When considering the design of a new airliner concept, a preliminary design study is necessary to optimize the location of the supplementary nacelles. The nacelles, which only hold the electrical motor, can also be considered retractable, as is usual for a RAT (Ram Air Turbine). Please note that in the hybrid propulsion context, the RAT function can be clearly allocated to the electric motor, with the advantages of optimizing drag at high speed, taking into account installation problems.

Keywords: hybrid propulsion, electric taxi, nacelles location, RAT, propeller design, retractable nacelle, energy storage system.

\section{Introduction}

The authors, within their research group, are focused on exploring hybrid propulsion and all related features and complexities of applying it to modern aircraft. (Chiesa et al. 2013) and (Fusaro 2014) previously show that electric taxi capabilities could be the most interesting aspect for investigation. Electric taxi means the capability of performing on-ground movements, such as moving from the airport's ramp to the runway and vice versa without using internal combustion engines. Another typical use of this kind of innovative propulsion is the over-boost capability, i.e. the use of electric power for a short period of time during which the take-off manoeuvre is carried out. This aspect should be studied properly, because it can allow the size reduction of main thermal engines, usually designed in order to comply with the take-off requirements.

It should be noticed that in the case of pistonprop or turboprop aircraft, the propeller is the element using which it is possible to add up the power coming from different energy sources, or to completely substitute traditional thermal power with an electric one. Obviously, since we are dealing with jet aircraft, this is not possible and alternative solutions should be evaluated. In particular, in this article, the authors propose to design auxiliary propellers, driven by electric motors, as sketched in Figure 1. In this way, it is possible to add the propulsive action of the jet engines to the thrust produced by separated electrically operated propellers.

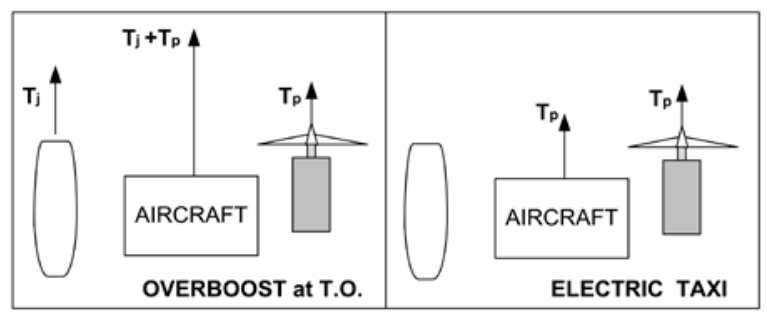

Fig. 1. Hybrid propulsion scheme for jet propelled aircraft

In particular, this figure illustrates the possibility of performing both the over boost and the electric taxi for this innovative hybrid jet aircraft. Moreover, it reveals that the different thrusts are not added to the same element and this implies additional problems that should be taken into account. The most relevant one is the difficulty of installing the electric motors, which should be mounted separately from the main engine nacelles. This implies the impossibility of using these electric machines as starters, as it is usual for turboprop and pistonprop aircraft. Conversely, it should be feasible to employ the propellers to drive the connected electric motors in order to recover the energy storage system; this is possible due to the capability of the propeller to both use and produce power.

In the following sections, the Airbus A320 is reported as a case study (see Fig. 2 for technical details).

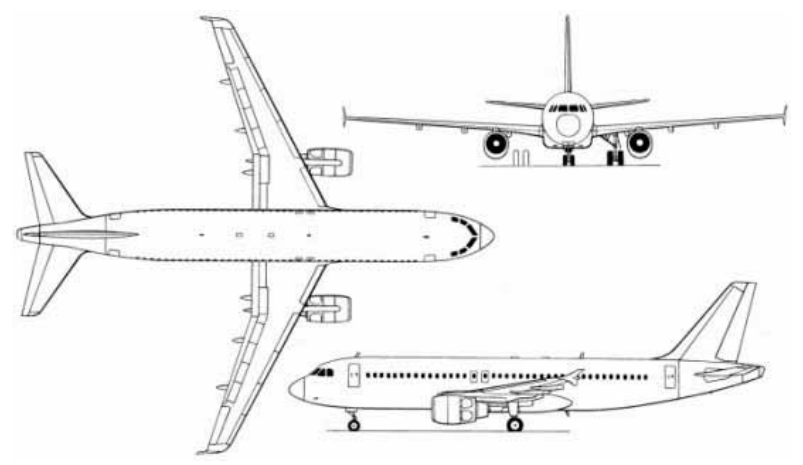

Fig. 2. AIRBUS A 320. Three view drawing and technical data

Please note that the A320 considered in this paper is an assumed updated version of this aircraft, as far as the on board system configuration is concerned. In particular, considering the actual trend (Chiesa et al. 2012b) an all-electric aircraft (AEA) configuration has been defined with the secondary power generation completely based on three 230 VAC WF starter/generators, each rated at $150 \mathrm{kVA}$, one per engine and Auxiliary Power Unit (APU). Neither hydraulic system nor engine-bleed is present. The definition of this new system configuration has been performed on the basis of the ASTRID methodology, proposed by the authors in (Chiesa et al. 2012a).

\section{Hybrid propulsion for the reference aircraft, Airbus A320}

The hybrid propulsion system designed for the A320 has the primary goal of allowing the aircraft to perform electric taxi manoeuvres. As far as the over boost capability is concerned, the same propeller configuration proposed for the electric taxi optimization will be used in order to 
avoid weight increases. Conversely, the increase of the energy storage system should be taken into account.

With the attention focused on the electric taxi, the following data have been considered in order to obtain the power requirement estimation:

- distance from ramps to the runway threshold (and vice versa): $\mathrm{L}_{\mathrm{ta}}=3000 \mathrm{~m}$;

- average speed during taxi: $\mathrm{V}_{\mathrm{ta}}=10 \mathrm{~m} / \mathrm{s}$;

- multiplying coefficient for braking actions and accelerations: $\mathrm{F}=1.5$;

- friction coefficient (wheels and runway): $\mathrm{f}=$ 0.024 .

The friction coefficient assumed is rather conservative for a paved runway and low speed operation. In this study, semi-prepared or grass runways are not considered. Moreover, the assumed value has already been examined in the specialized literature, as outlined in (Lausetti 1992).

Considering a Take Off Gross Weight (TOGW) of about $77000 \mathrm{~kg}$, it is possible to evaluate the drag force during taxi phase $\left(D_{\mathrm{r}}\right)$ as highlighted in Eq. (1):

$$
D_{r}=T O G W \cdot f=18129 \mathrm{~N} \text {. }
$$

It is worth noting that Eq. (1) is defined with the terms of a conservative hypothesis, in which the aircraft also performs the taxi after landing with the TOGW. It is assumed that the use of a four blade propeller is a good compromise to obtain a compact propeller diameter with a consequent increase in propeller maximum speed. The propeller diameter is considered a variable and is calculated after the assumption of the others parameters.

During taxi, it is assumed a propeller with a pitch angle $(\beta)$ of $15^{\circ}$, the ratio $\gamma$ of aircraft speed $\left(V_{t a}\right)$ to propeller tip speed $(\Omega \mathrm{R})$ is considered to be constant as $\Omega \mathrm{R}$ is set to $300 \mathrm{~m} / \mathrm{s}$ in order to avoid transonic phenomena. Considering these assumptions, from Figure 3, which refers to a NACA four-blade propeller, it is possible to obtain the following coefficients: traction $(\tau)$, torque $(\chi)$ and efficiency $(\eta)$ for $\beta=15^{\circ}$, as pointed out with the blue arrows in Figure 3.

In order to contain the propeller size, the entire necessary traction of $18129 \mathrm{~N}$ is distributed among four propellers. Therefore, each propeller has to generate at least $4532 \mathrm{~N}$. To calculate the correct propeller radius an iterative calculation is performed assuming several propeller radiuses. For each radius value, as described in Table 1, the rotational propeller speed $\Omega$ is calculated, avoiding transonic speed at propeller tips and as a function of the coefficients $\tau, \chi$ and $\eta$. Through these coefficients and by means of the following equations, it is possible to calculate the traction $(\mathrm{T})$ and torque $(\mathrm{C})$ required by the propeller:

$$
\begin{aligned}
& T=\tau \cdot \rho \cdot \Omega^{2} \cdot R^{4} ; \\
& C=\chi \cdot \rho \cdot \Omega^{2} \cdot R^{5} .
\end{aligned}
$$

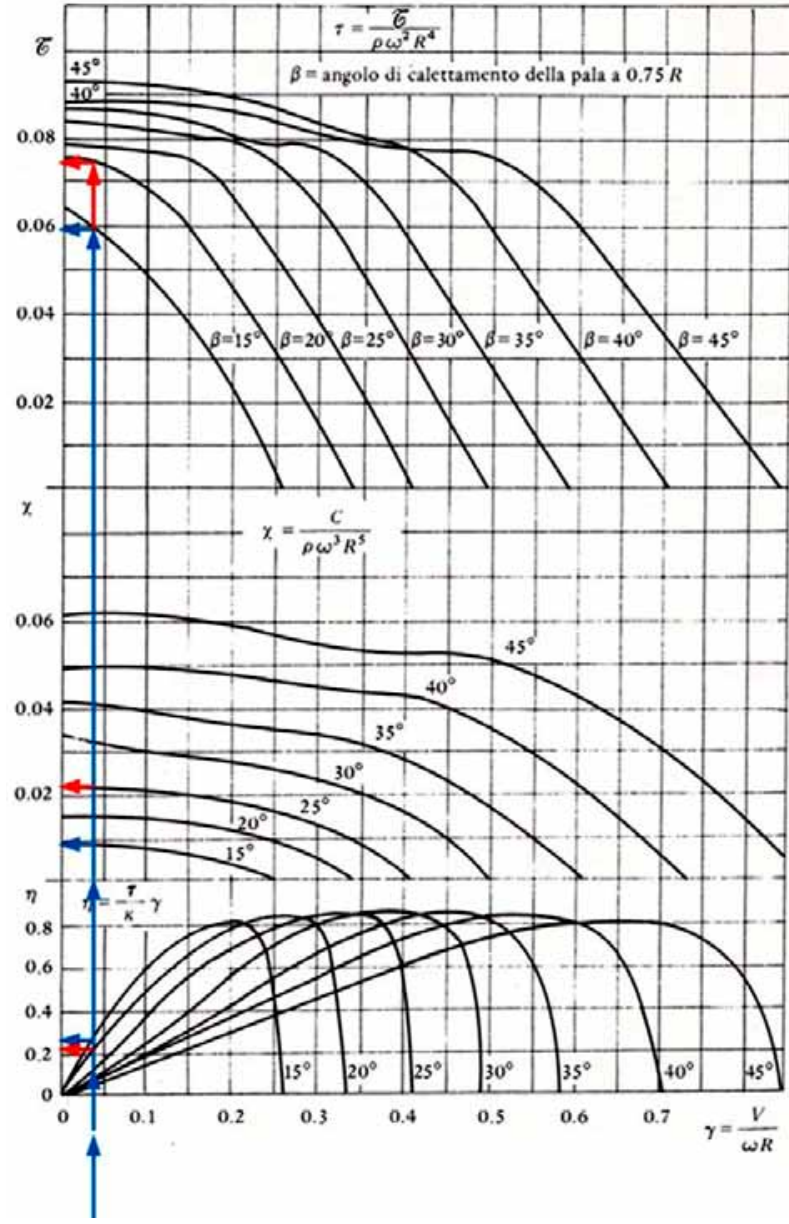

Fig. 3. Propeller Plots (NACA four-blades). From (Lausetti 1992)

The power required $(\mathrm{P})$ is calculated by:

$$
P_{\text {prop }}=C \cdot \Omega \text {, }
$$

where: $\rho$ - air density; $\tau$ - thrust coefficient; $\chi$ - torque coefficient; $\Omega$ - propeller rotational speed; $\mathrm{R}$ - propeller radius; $\mathrm{T}$ - thrust; $\mathrm{C}$ - torque; $\mathrm{P}_{\text {prop }}$ - power; $\eta$ - propeller efficiency.

It is worth noting that, using equation (5), a calculated value of efficiency ( $\eta_{\text {CALCULATED }}$ ) can be obtained. These values are almost equal to those obtained by Figure 3 .

$$
\eta_{\text {CALCULATED }}=\frac{T \cdot V_{t a}}{P_{\text {prop }}} \text {. }
$$

Table 1 shows that the propeller which produces a traction close to the required $4532 \mathrm{~N}$ has a radius of $0.82 \mathrm{~m}$ and needs a power of about $200 \mathrm{~kW}$. To confirm the result obtained with a propeller pitch angle of $15^{\circ}$, the same calculation has been performed with $\beta=20^{\circ}$. The coefficients $\tau, \chi$ and $\eta$ are calculated by means of graphs shown in Figure 3 and are indicated with red arrows.

In this case the propeller with $\mathrm{R}=0.75 \mathrm{~m}$ satisfies the traction requirement (see Table 2). This means a reduction of propeller diameter of $0.14 \mathrm{~m}$ in comparison to the propeller calculated with $\beta=15^{\circ}$. On the other hand, the smaller propeller requires a greater power $(215 \mathrm{~kW})$. 
Table 1. Parametric study of propeller performance vs radius $\mathrm{R}$ with $\beta=15^{\circ}$

\begin{tabular}{l|l|l|l|l|l|l|l}
\hline $\mathrm{R}[\mathrm{m}]$ & 0.75 & 0.8 & $\mathbf{0 . 8 2}$ & 0.85 & 0.9 & 0.95 & 1 \\
\hline$\Omega[\mathrm{rad} / \mathrm{s}]$ & 400 & 375 & 365.85 & 352.94 & 333.34 & 315.79 & 300 \\
\hline$\gamma=\mathrm{V} /(\Omega \mathrm{R})$ & 0.033 & 0.033 & 0.033 & 0.033 & 0.033 & 0.033 & 0.033 \\
\hline$\tau$ & 0.06 & 0.06 & 0.06 & 0.06 & 0.06 & 0.06 & 0.06 \\
\hline $\mathrm{T}[\mathrm{N}]$ & 3720.94 & 4233.60 & $\mathbf{4 4 4 7 . 9 3}$ & 4779.34 & 5358.15 & 5970.04 & 6615.00 \\
\hline $\mathrm{c}$ & 0.009 & 0.009 & 0.009 & 0.009 & 0.009 & 0.009 & 0.009 \\
\hline $\mathrm{C}[\mathrm{Nm}]$ & 418.61 & 508.03 & 547.09 & 609.37 & 723.35 & 850.73 & 992.25 \\
\hline$P_{\text {prop }}[\mathrm{kW}]$ & 167.44 & 190.51 & $\mathbf{2 0 0 . 1 6}$ & 215.07 & 241.12 & 268.65 & 297.68 \\
\hline$\eta($ calculated $)$ & 0.22 & 0.22 & 0.22 & 0.22 & 0.22 & 0.22 & 0.22 \\
\hline
\end{tabular}

Table 2. Parametric study of propeller performances vs radius $\mathrm{R}$ with $\beta=20^{\circ}$

\begin{tabular}{l|l|l|l|l|l|l|l}
\hline $\mathrm{R}[\mathrm{m}]$ & $\mathbf{0 . 7 5}$ & 0.8 & 0.82 & 0.85 & 0.9 & 0.95 & 1 \\
\hline$\Omega[\mathrm{rad} / \mathrm{s}]$ & 400 & 375 & 365.85 & 352.94 & 333.33 & 315.79 & 300.00 \\
\hline$\gamma=\mathrm{V} /(\Omega \mathrm{R})$ & 0.033 & 0.033 & 0.033 & 0.033 & 0.033 & 0.033 & 0.033 \\
\hline$\tau$ & 0.076 & 0.076 & 0.076 & 0.076 & 0.076 & 0.076 & 0.076 \\
\hline $\mathrm{T}[\mathrm{N}]$ & $\mathbf{4 7 1 3 . 1 9}$ & 5362.56 & 5634.04 & 6053.83 & 6786.99 & 7562.05 & 8379.00 \\
\hline$\chi$ & 0.016 & 0.016 & 0.016 & 0.016 & 0.016 & 0.016 & 0.016 \\
\hline $\mathrm{C}[\mathrm{Nm}]$ & 744.19 & 903.17 & 972.61 & 1083.32 & 1285.96 & 1512.41 & 1764.00 \\
\hline $\mathrm{P}_{\text {prop }}[\mathrm{kW}]$ & $\mathbf{2 1 4 . 2 4}$ & 243.75 & 256.09 & 275.17 & 308.50 & 343.73 & 380.86 \\
\hline$\eta($ calculated) & 0.22 & 0.22 & 0.22 & 0.22 & 0.22 & 0.22 & 0.22 \\
\hline
\end{tabular}

These results confirm the convenience of using a small propeller pitch angle when the propeller is used in the taxi phase, i.e. at low speed. For that reason, the propeller selected is the one with a radius of $0.82 \mathrm{~m}$.

Taking into account the design of the energy storage system, the energy (E) required during the taxi phase is given by equation (6):

$$
E=\frac{\left[\left(N_{\text {prop }} \cdot P_{\text {prop }}+\Delta_{2-\text { aryPow }}\right) \cdot \frac{L_{t a}}{V_{t a}} \cdot \frac{F}{3600}\right]}{\eta_{\text {discharge }}},
$$

where: $\mathrm{N}_{\text {prop }}$ - number of propeller used during taxi $=4$; $\mathrm{P}_{\text {prop }}$ - power required by each propeller (see Table 1$)=$ $200 \mathrm{~kW}$;

$\mathrm{L}_{\mathrm{ta}}$ - distance from gate to runway threshold $=3000 \mathrm{~m}$;

$\mathrm{V}_{\mathrm{ta}}$ - average speed during taxi $=10 \mathrm{~m} / \mathrm{s}$;

$\mathrm{F}$ - coefficient to take into account the increase in energy required due to stops and deceleration during taxi $=1.5$; $\Delta_{2 \text {-ary Pow }}$ - power required by on-board systems during taxi: brakes, steering, avionics, environmental control system (ECS), lights, etc. The power necessary to start the APU, to start the main engine prior to take off, is taken into account and assumed as $60 \mathrm{~kW}$, i.e. the half of the power supplied by APU;

$\eta_{\text {discharge }}$ - battery discharge efficiency $=0.7$.

The energy required by the energy storage system is $150 \mathrm{kWh}$ and the taxi phase lasts 450 s, i.e. 7.5 minutes, also considering braking and acceleration actions.

Starting from the energy required, a first estimation of the characteristics of the battery system is now possible.
By selecting an advanced energy storage system and using the statistical diagram shown in Figure 4, a weight and volume estimation is obtained for the A320 test case:

$-\mathrm{E} \cdot 1000 / 200=750 \mathrm{~kg}$. This represents the weight of the storage system which is increased to $800 \mathrm{~kg}$ to consider the weight of the battery management system (BMS) useful to manage the charge and discharge of the advanced batteries;

- E $\cdot 1000 / 300=500 \mathrm{~L}$. This figure represents the volume of the storage system.

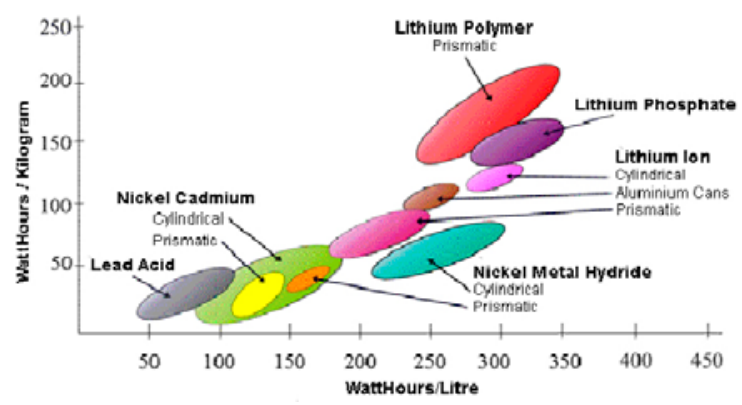

Fig. 4. Volume and weight for several type of energy storage systems

\section{Possible configurations of the hybrid propulsion system}

As a result of the assumptions explained in Section 1, the hybrid propulsion system is composed of four propellers with four blades and with a diameter of $1.64 \mathrm{~m}$. Each propeller is powered by an electrical engine with a nominal power of $200 \mathrm{~kW}$. For this purpose, 
considering the significant amount of power required, a high voltage direct current (HVDC) motor-generator (i.e. electrical engine supply with $270 \mathrm{~V}$ ) is considered. In particular, the electrical engine could be a switched reluctance machine (SRM) (Chiesa et al. 2007). This technology has advantages in terms of reliability, low acquisition cost and simple switching mode of operation, i.e. the change from motor to generator operation and vice versa. This last characteristic is valuable considering the opportunity to recharge the energy storage system when, for example, the airplane is in the descent phase and the propellers can be used as the RAT. For the SRM technology, it is possible to hypothesize a power density of $0.65 \mathrm{~kg} / \mathrm{kW}$ and a density of $3.8 \mathrm{~kg} / \mathrm{dm}^{3}$. The diameter of the electrical engine has to be small in order to achieve a more aerodynamic shape for the supplementary nacelle. An electrical engine with a small diameter is not optimized to produce a high torque; however, this characteristic is not in contrast with the value of the coefficient $\chi$. Therefore, the SRM dimensions are defined assuming a diameter of $0.22 \mathrm{~m}$ and a length of $0.88 \mathrm{~m}$ and, using the density previously defined, a weight of $130 \mathrm{~kg}$ can be estimated. As regards the propeller weight, with similar assumptions, it is possible to estimate a weight of $20 \mathrm{~kg}$. In order to optimize the aerodynamic behaviour of the electric propulsion system, a tandem configuration is considered, as shown in Figure 5. Hence, each nacelle contains two electrical motors; the front propeller is in a tractor configuration and the other one in a pusher configuration. From (Lausetti 1992), if the distance between two tandem propellers is equal to their diameters, the front propeller is not perturbed by the pusher one and the pusher propeller also shows an increment in propulsive efficiency. To simplify the calculation, this increment is not considered and the propulsive action of the two propellers is summed up as if they were isolated.

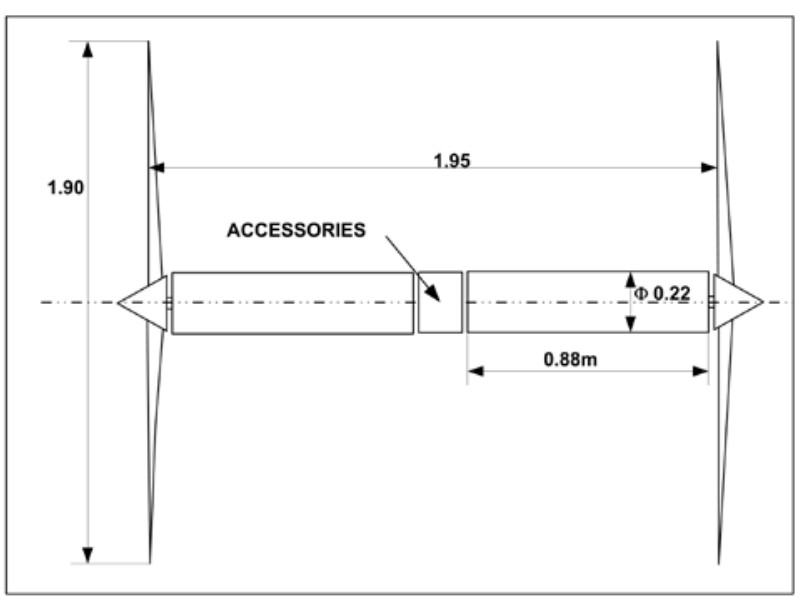

Fig. 5. Two propellers and electric motor-generators in a tandem configuration
After the selection of the tandem configuration, the subsequent matter is where, on the aircraft, the two nacelles should be placed. This is a significant topic because, during the large part of the flight, the propellers are not operative and their aerodynamic drag has to be minimized. This can be done by setting the propellers in a feathered position, i.e. changing the propeller $\beta$ angle till the blade sections are aligned with the aerodynamic flow (Fig. 6).

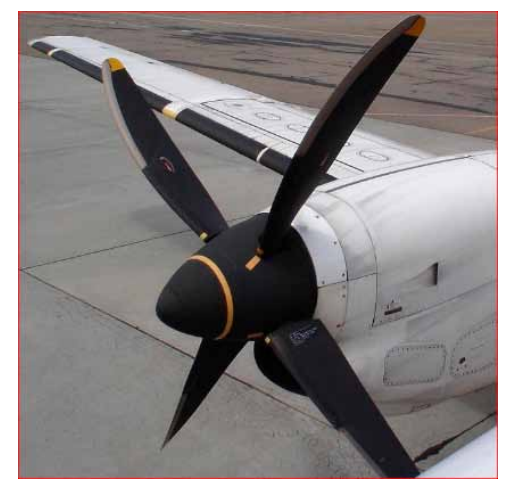

Fig. 6. Propeller in a feathered position

Another solution, common for aircraft models and for some motor gliders (Tervamaki 2014), is the use of propellers with folding blades. In Figure 7, a typical solution adopted for motor gliders with a pusher propeller is shown. In this case, the propeller blades are folded backwards, in order to align them with the propeller spin axis and to remain inside the aerodynamic flow of the propeller hub. The folding mechanism is usually constituted of springs which automatically fold the blades when the propeller is stopped, i.e. when the aerodynamic and centrifugal blades forces drop to a predefined value. Otherwise, when the propeller starts to rotate, the blades move from the folding position forward from $90^{\circ}$ until reaching a perpendicular position relative to the spinning axis. The movement of the blades is mechanically limited so as to avoid the aerodynamic forces deflecting the blades to an angle greater than $90^{\circ}$.

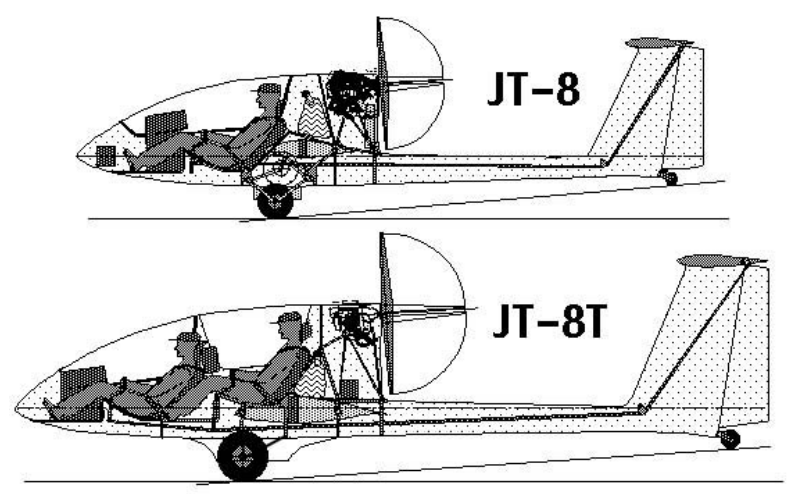

Fig. 7. Propeller with folding blades for motor glider application. From (Tervamaki 2014) 
The next step is to examine how the folding blade propellers can be introduced into the nacelle with the two tandem propellers and electric motor-generators previously proposed. The results of a first design are depicted in Figure 8; the following characteristics can be derived:

- for a propeller in puller configuration, the blades can be folded backwards as for the motor glider application (Fig. 7) with the difference that the blades are folded close to the lateral portion of the nacelle where the electric engines are installed;

- the blades of the pusher propeller are folded forwards and, as for puller propeller, the blades remain lean to the nacelle skin. This solution, as shown clearly in Figure 8, has some drawbacks, since there is a lack of a mechanical stop for the blade movement due to the aerodynamic traction forces when the propeller is rotating. To avoid this problem, it is necessary to add actuators or lock devices to maintain the blades perpendicular to the rotation axis;

- otherwise, if a greater nacelle length is allowed, when the electric propulsion system is not in function, the blades of the pusher propeller can be folded backwards as for the puller one. In this case the propeller system, as shown in Figure 9, does not need an additional locking system.

Finally, it is possible to complete a preliminary installation study of the hybrid propulsion system on the Airbus A320 airplane. Since the significant increase of the aerodynamic drag is due to the two propellers, even when the blades are feathered, a non-folding blades propeller is not considered. Two installation solutions as depicted in Figure 10 are proposed:

- the first solution: the nacelles are installed externally, are non-retractable and above the horizontal tail of the aircraft. When the electric propulsion is not operative, the blades are folded backwards, for both the pusher and puller propeller;

- the second solution: the nacelles are retractable into the fuselage, below the pavement of the passengers' cabin and backwards with respect to the nose landing gear position. When the two nacelles are retracted, the zero lift drag remains the same as for the standard A320. However, to enable this solution, extension and retraction mechanisms with dedicated actuators have to be considered. Moreover, the size of the nacelles, when

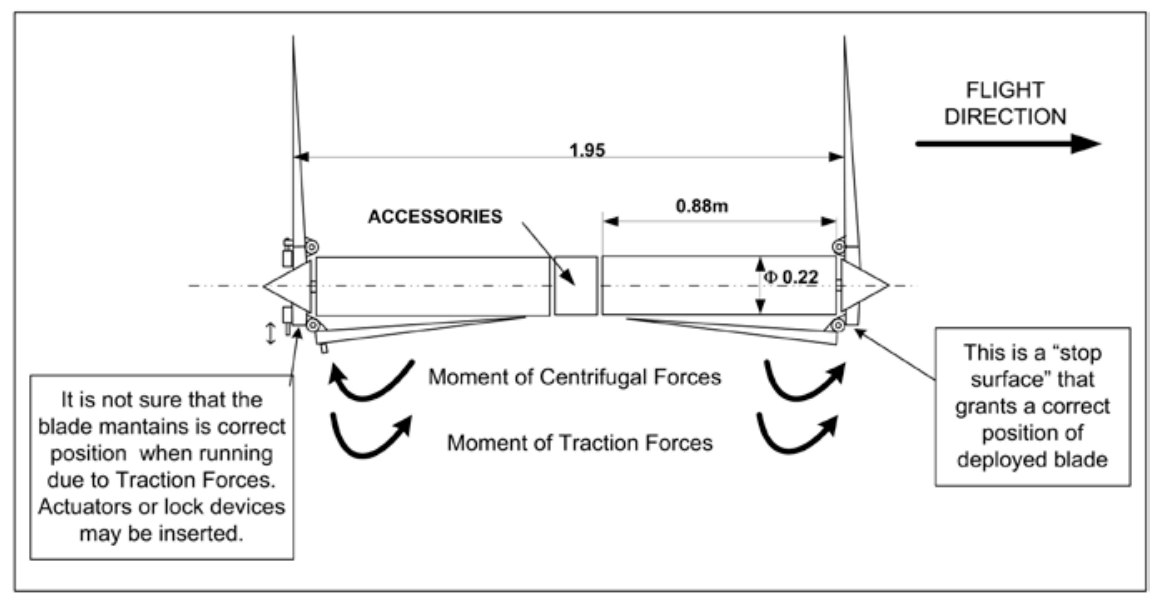

Fig. 8. Propellers with folding blades: different solutions for puller and pusher propellers

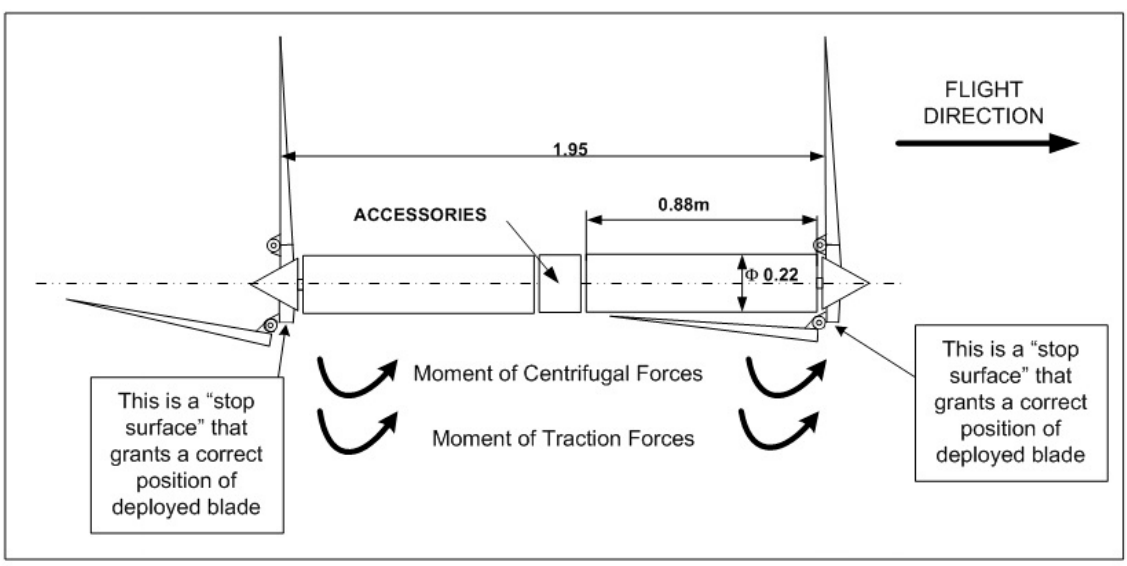

Fig. 9. Propellers with folding blades: similar solutions for puller and pusher propellers 


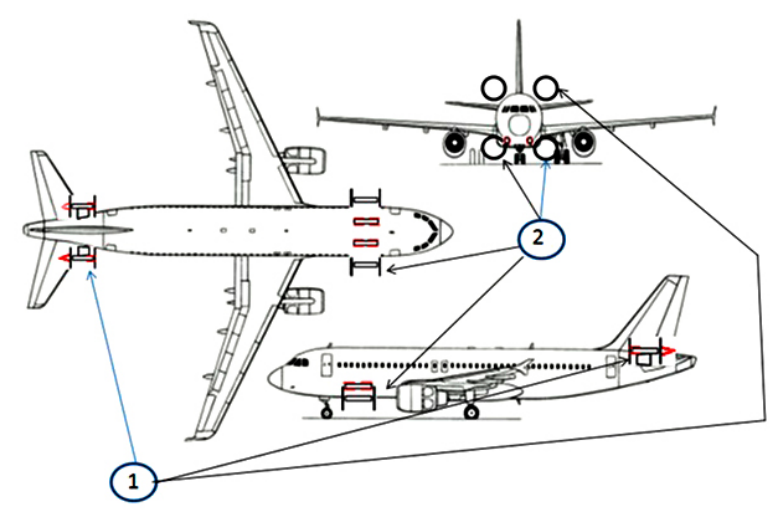

Fig. 10. Two solutions of the hybrid propulsion system installation

the electric propulsion is not operating, has to be compact. Therefore, the solution that involves a more complicated blade lock mechanism, shown in Figure 8, is chosen.

\section{Hybrid propulsion system for a jet: an operation and feasibility study}

To perform a preliminary evaluation of the feasibility of the proposed hybrid propulsion system, the difference between the two solutions, showed in Figure 10 in the previous section, can be neglected. Certainly, in a more accurate evaluation study these two solutions could lead to different results and a possible trade-off in terms of different weight and cost of the two solutions could be of interest.

In Figure 11, a typical operating cycle of the hybrid propulsion system is presented within the aircraft mission profile. The diagram starts by defining the behaviour of the hybrid propulsion system during cruise phase, then it continues with the descent, landing, taxi from the runway threshold to the airport's ramp, turnaround operation, taxi from the ramp to the threshold, and take-off and climb.

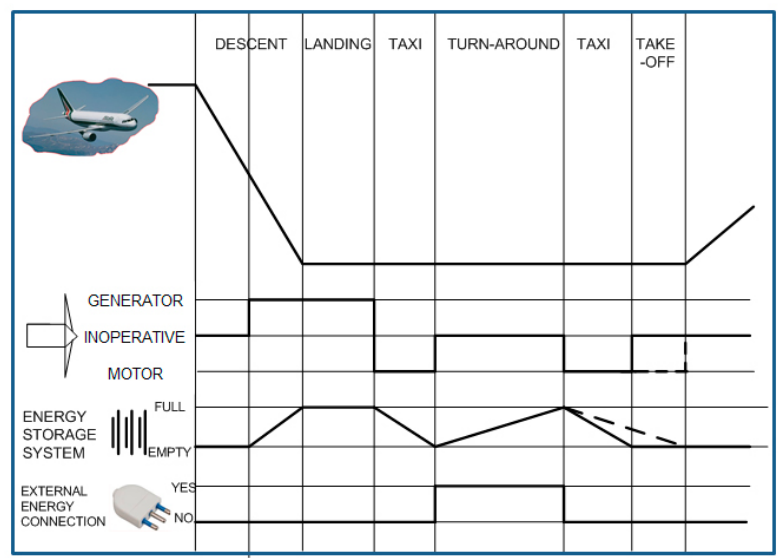

Fig. 11. Hybrid propulsion system operation cycle from the aircraft's descent to take-off
During the descent phase, it is useful to perform the charging of the energy storage system in order to use the stored energy for the following taxi manoeuvres from the runway to the airport's ramp. The four propellers, described in the previous sections, used during the taxi to move the aircraft with the internal combustion engine turned-off can be employed as the RAT during descent. This operation requires the extraction of the nacelles, if the solution with the nacelle storage inside the fuselage is adopted, and, for both configurations, the blades have to be unfolded. Then, the blade pitch angle has to be set to optimize the use of the propeller as an energy generator. To quantify the amount of energy generated, considering the present study as a preliminary analysis, the behaviour of the propeller used to generate energy has to be considered similar to the behaviour of the RAT (Chiesa 1980). This analysis is based on a technical document produced by a reliable source (Zolidis 2006). In this document, a RAT with a diameter of $1.57 \mathrm{~m}$ is capable of producing $63.5 \mathrm{~kW}$ at $67 \mathrm{~m} / \mathrm{s}$. In a conservative way, since the adopted propeller has a grater diameter ( $1.64 \mathrm{~m}$. and four blades, it is assumed that the propeller has to produce at least $100 \mathrm{~kW}$ at $67 \mathrm{~m} / \mathrm{s}$. The $\beta$ angle must be set avoiding battery overload in the case that the aircraft flies at a higher speed, since the above mentioned speed of $67 \mathrm{~m} / \mathrm{s}$ is closer to the minimum speed of the A320.

Since the energy required for taxi operation is 150 $\mathrm{kWh}$ and the assumed charge efficiency $\eta_{\text {charge }}=0.85$, it is possible to define the following equation:

$$
150 \mathrm{kWh}=4 \cdot 100 \mathrm{~kW} \cdot t_{\text {charge }} \cdot \eta_{\text {charge }},
$$

where the charge time $\left(\mathrm{t}_{\text {charge }}\right)$ can be calculated as: $\mathrm{t}_{\text {charge }}=0.44 \mathrm{~h}=26.4 \mathrm{~min}$.

Since there is a lack of information about the propeller performance when its rotation is led by aerodynamic force, the calculation of the additional drag due to the propeller will be calculated in further studies. However, as the first assumption, the value of the propeller drag is not considered as sufficient to change the aircraf's mission profile significantly.

It is worth noting that, during the landing phase, the four propellers contribute considerably to the deceleration of the aircraft. However, regarding the energy accumulation during the landing, the time to store the kinetic energy is so short that the recharge operation becomes inefficient due to the intense charging current. For this reason, the landing phase is not taken into account for the energy storage calculation making an additional conservative assumption.

During the following taxi operation from the runway threshold to the airport's ramp, the hybrid propulsion system uses up almost all of the energy stored during the descent. Considering the previously obtained 
results, each of the four propellers has to produce $5970 \mathrm{~N}$ of thrust for $450 \mathrm{~s}$. In order to calculate the amount of fuel saved using the electric propulsion, a traditional A320 which performs taxi using the two main turbofans and an APU is considered. It is possible to assume a main engine $\mathrm{SFC}=0.6 \mathrm{~kg} /(\mathrm{kg} \mathrm{h})$, and, considering the total amount of thrust necessary to perform taxi, $183 \mathrm{~kg}$ of fuel is needed. During taxi, the APU is also turned on to provide energy to the aircraft on-board systems. The APU produces $60 \mathrm{~kW}$ of power for $450 \mathrm{~s}$. Consequently, assuming an APU SFC $=0.4 \mathrm{~kg} /(\mathrm{kg} \mathrm{h})$, it is possible to calculate the necessary fuel as being $3 \mathrm{~kg}$. Therefore, the total amount of fuel saved is $186 \mathrm{~kg}$ and taking into account the subsequent taxi phase (from the airport's ramp to the runway threshold) the fuel saved is $392 \mathrm{~kg}$. From Figure 11, it is possible to note that the energy storage system is designed to supply the amount of energy necessary to perform only one taxi phase. This is due to the need to reduce the weight of the hybrid propulsion system. Between the two taxi phases, when the aircraft is on the airport's ramp and is performing the turn-around operations, the system is connected to an external energy supply which has to:

- replace the APU, providing secondary power during the turn-around operations. Also, in this case, the amount of energy supplied by the APU can be assumed to be equal to $60 \mathrm{~kW}$. Since with a standard aircraft this amount of energy is produced by the APU, it is necessary to add an additional $12 \mathrm{~kg}$ of fuel burned (assuming a turn-around time of $0.5 \mathrm{~h}$ ), thus obtaining that the total amount of fuel saved per flight is $404 \mathrm{~kg}$;

- charge the energy storage system in order to perform the following taxi and take-off phases with the hybrid propulsion system. Considering the turn-around time, the charging of the batteries can be performed with a high value of $\eta_{\text {charge }}$.

As a result of this analysis, for an aircraft comparable to the A320, the feasibility of a mission in which the internal combustion engine is not used from the landing to the following take-off is verified. Hence, the following analysis is carried out with the aim of understanding whether the hybrid propulsion is feasible in terms of weight. Previously in this paper, the weight of the electric motor-generator (130 kg each) and the composite propeller was estimated (20 kg each), obtaining a total weight of $600 \mathrm{~kg}$. Thus, each nacelle, including two electric engines and propellers, weights $300 \mathrm{~kg}$. Furthermore, focusing on the first configuration (i.e. fixed nacelles), it would be necessary to calculate the extra weight of fuel to take into account the effect of the additional drag of the nacelles. Likewise, considering the second configuration (i.e. retractable nacelles), the extra weight of the retraction and extraction mechanism should be estimated.
However, the evaluation of these additional weights does not seem achievable at this level of analysis and is, therefore, not taken into account.

In conclusion, focusing on the elements that are evaluated in this preliminary study, it is possible to summarize the weight estimation as:

- weight of the nacelles (electric motor-generators and propellers) $=600 \mathrm{~kg}$;

- weight of the energy storage system (BMS included) $=800 \mathrm{~kg}$;

- weight of fuel saved during the landing, taxi, and turn-around phases $=402 \mathrm{~kg}$.

It is worth noting that, using the hybrid propulsion, also, the weight of the RAT could be reduced. The RAT is provided for almost all civil transport aircraft in case of an emergency situation, and the propeller connected with the electric motor-generator of the hybrid propulsion could easily replace it. Focusing on the aircraft operating cost, the effect of the introduction of the hybrid propulsion system has to be multiplied for the great number of flights performed by transport aircraft. In particular, it is important to take into account the cost of fuel saved and the reduction in airport taxes due to the low noise and pollution emissions.

As a final point, it is useful to outline the opportunity to use the thrust produced by the propellers not to replace the internal combustion engines but to produce additional thrust jointly with them during the take-off manoeuvre. This important topic, which is typical for the hybrid propulsion system, deserves to be investigated in more detail in a separate work. However, to continue with the preliminary analysis, this operation case is indicated with dashed lines in Figure 11. In this case, the electric motors are also activated during the take-off, and the energy storage system has to supply them after the taxi from the ramp to the runway threshold and APU start. The effect of the additional $2400 \mathrm{~kg}$ of thrust produced by electric propulsion on the $24400 \mathrm{~kg}$ produced by the internal combustion engine represents a $10 \%$ increase in the total thrust. This additional thrust could be particularly advantageous for hot and high take-off conditions. Moreover, as illustrated in Figure 12 (figure taken from the conceptual design methodology employed by the authors (Fioriti 2014)), since the take-off is usually the most stringent requirement, there is an opportunity to replace part of the internal combustion engine thrust with the one produced by the electric engine. This opportunity leads to two additional options:

- employing the same internal combustion engines and obtaining a fuel saving, reduction of noise and chemical pollution and decrease of the probability of an engine failure due to the de-rating operation; 


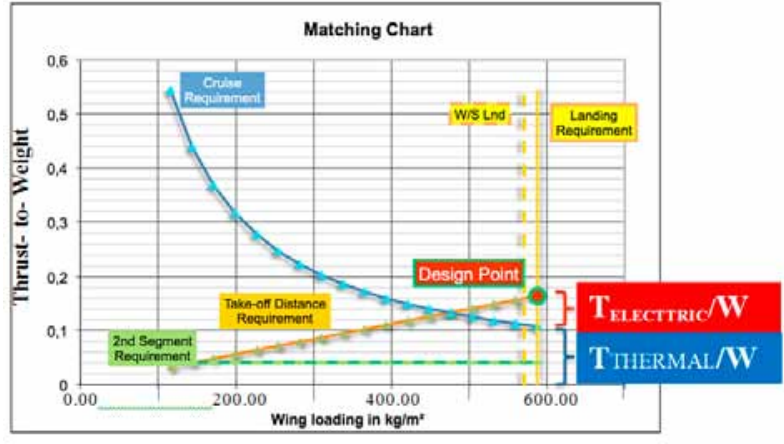

Fig. 12. "Matching chart" plot showing the benefit of the over boost at take-off. From (Fioriti 2014)

- replacing the internal combustion engine with a smaller one. In this case the advantages are evident in terms of acquisition cost and weight.

The use of the electric propulsion in the take-off phase as well entails an increase of the energy storage weight. On the contrary, considering the electric motor-generators and propellers, no changes are needed. In order to evaluate the growth in battery weight, it is possible to assume that the use of the system has to be extended for an additional $60 \mathrm{~s}$ (the duration of the takeoff phase), which compared to the previous $450 \mathrm{~s}$ appears feasible. Therefore, it is believed that this increase in weight is quite restrained considering the small increment of the discharge efficiency due to the augmented battery capacity. Moreover, during the warm-up of the main engines, waiting for other aircraft operations and pre-flight checks, the main engine could charge the energy storage system, even if it is a short time.

\section{Conclusions}

The hybrid propulsion system, for civil transport aircraft, is a subject that is not yet well defined, in contrast to other aircraft typology, such as general aviation. In this paper, the feasibility of this kind of propulsion is preliminarily demonstrated. Among other possible configurations, the one in which two retractable nacelles are used to perform the green taxi without the use of the internal combustion engine, and it is able to recover energy during descent phase seems promising. Some important issues, such as the opportunity to use the electric propulsion to assist the take-off phase and the estimation of the weight and dimensions of the mechanism needed to extract and retract the nacellesare still not defined. In particular, concerning the assisted take-off, further investigations will focus on the trade-off analysis necessary to evaluate the optimal solution between the reductions of the internal combustion engine and the de-rated use of the engine. Moreover, a further and more detailed feasibility analysis would be indispensable to evaluate the possible weight reduction of the electric motor-generators and energy storage system, taking into account the latest technologies which can be employed in the short term and estimating the possible operating cost reduction by considering the savings in terms of fuel and airport taxes.

\section{Acronyms}

$\beta$ - propeller pitch angle;

$\gamma$ - ratio of aircraft speed to propeller tip speed;

$\eta_{\text {CALCULATED }}$ - propeller efficiency calculated;

$\eta_{\text {charge }}$ - battery charge efficiency;

$\eta_{\text {discharge }}-$ battery discharge efficiency;

$\rho$ - air density;

$\Omega$ - rotational propeller speed;

AC - Alternate current;

AEA - All electric aircraft;

APU - Auxiliary power unit;

ASTRID - Aircraft on board systems sizing and tradeoff analysis in initial design;

BMS - Battery management system;

$\mathrm{C}$ - Torque required by propeller;

$\mathrm{D}_{\mathrm{r}}$ - Drag force during taxi;

$\mathrm{E}-$ Energy required during taxi;

ECS - Environment control system;

F - Multiplying coefficient for braking actions and accelerations;

$\mathrm{f}-$ Friction coefficient (wheels and runway): $\mathrm{f}=0.024$;

HVDC - High voltage direct current;

$\mathrm{L}_{\mathrm{ta}}$ - Distance from gate to runway threshold;

OEW - Operating empty weight;

$\mathrm{P}_{\text {prop }}$ - Power required by propeller;

$\mathrm{R}$ - Propeller radius;

RAT - Ram air turbine;

SFC - Specific fuel consumption;

SRM - Switched reluctance machine;

$\mathrm{T}$ - Propeller traction;

$\mathrm{t}_{\text {charge }}$ - battery charge time;

TOGW - Take Off Gross Weight;

$\mathrm{V}_{\mathrm{ta}}-$ Average speed during taxi;

WF - Wild frequency.

\section{Disclosure statements}

The Authors declare to have no competing financial, professional or personal interests from other parties.

\section{References}

Chiesa, S. 1980. Confronto tra sistemi di generazione di potenza in condizioni di emergenza a bordo di velivoli, Ingegneria No. 11-12 (in Italian).

Chiesa, S.; Corpino, S.; Fioriti, M.; Furlan, A.; Brunetti, F.; Fusaro, R. 2013. Hybrid configuration - advanced A.P.U. concept for future turboprop, in the XXII Conference AIDAA - Italian Association Aeronautics and Astronautics, 9-12 September 2013, Naples, Italy.

Chiesa, S.; Di Meo, G.; Fioriti, M.; Medici, G.; Viola, N. 2012a. ASTRID - aircraft on board systems sizing and trade-off 
analysis in initial design, in Research and Education in Aircraft Design - READ 2012, Brno, Czech Republic.

Chiesa, S.; Fioriti, M.; Viola, N. 2012b. Methodology for an integrated definition of a system and its subsystems: the case-study of an airplane and its subsystems, in Systems Engineering - Practice and Theory. INTECH. ISBN: 978953-51-0322-6. http://dx.doi.org/10.5772/34453

Chiesa, S.; Viola, N.; De Iacovo, V.; Stesina, F. 2007. Nuovo sistema di generazione elettrica a $270 \mathrm{Vdc}$ a bordo dei velivoli e macchine elettriche "switched reluctance": attività al Politecnico di Torino, in XIX Congresso Nazionale della Associazione Italiana di Aeronautica e Astronautica - AI$D A A$ 2007, Forlì (FC), Italy (in Italian).

Fioriti, M. 2014. Adaptable conceptual aircraft design model, Advances in Aircraft and Spacecraft Science 1: 43-67. ISSN 2287-528X.

Fusaro, R. 2014. The advantage of a hybrid piston prop aircraft, accepted for presentation (Student Session) at READ 2014, 15-17 October 2014, Vilnius, Lithuania.

Lausetti, A. 1992. Decollo e Atterramento. Libreria Editrice Universitaria LEVROTTO \& BELLA. Turin, Italy (in Italian).

Tervamaki Engineering [online]. 2014 [cited August 2014]. Available from Internet: http://www.icon.fi/ jtki/index. html

Zolidis, M. J. 2006. Emergency airplane RATs. Hamilton-Standards (U.T.C.). 